\title{
Influence of Quenching Temperature on Microstructure and Properties of Cr5 steel
}

\author{
Ya-sha YUAN ${ }^{1, a}$, Wen-yan WANG ${ }^{1,2, ~ b}$, Jing-pei $\mathrm{XIE}^{1,2}$, Kai-hui $\mathrm{Xu}^{1}$, Hao-yin \\ Zhang $^{1}$, Ai-qin Wang ${ }^{1,2}$, Luo-li Li ${ }^{1,2}$ \\ ${ }^{1}$ College of mater Sic. \& Eng. Henan University of Science and Technology, Luoyang, 471023, China \\ ${ }^{2}$ Collaborative Innovation center of Non-Ferrous Materials, HenanProvince \\ aemail:269178090@qq.com, bemail: wangwy1963@163.com, 13525992122
}

Keywords: Cr5 steel; Quenching Temperature; Carbides; Hardness

\begin{abstract}
The microstructure (before and after quenching), phase (before quenching), carbide content and hardness were studied by scanning electron microscopy, X-ray diffraction, optical software and Rockwell hardness tester. The results indicate that carbides of Cr5 steel have different morphology features and obvious aggregation phenomenon, most carbides dissolve in the matrix after quenching, the carbides of not dissolving with small particles distribute in the martensite. The style of carbides before quenching have $\mathrm{M}_{7} \mathrm{C}_{3} 、 \mathrm{M}_{23} \mathrm{C}_{6}$ and $\mathrm{M}_{3} \mathrm{C}_{2}$. volume fraction of carbides gradually reduce with quenching temperature increase, and the temperature of carbides dissolving in the matrix is 970C. Cr5 steel hardness increases and later decreases with the quenching temperature increases, the peak hardness (54HRC) is achieved in the 970C.
\end{abstract}

\section{Introduction}

Backup roll is an important consumable part in the modern mill, mainly used to support the middle roll or work roll to work, to prevent the work roll due to the large radial stress and deformation, which affects the quality of the products[1,2]. Working nature and conditions of backup roll decide that they should have good wear resistance and fracture resistance, spalling resistance, and certain plastic toughness[4, 5]. At percent, the developing tendency of backup roll material present to reduce the carbon content, increase the chromium content, and add elements of molybdenum and vanadium, Cr5 steel is developed on the base $\mathrm{Cr} 3$, Cr4 steel in that principle. Compare with $\mathrm{Cr} 3$, Cr4 steel, the hardenability, hardness uniformity and comprehensive mechanical properties of Cr5 steel have greatly improved. Cr5 steel is primary materials to manufacture large backup roll of modern mill[6].

Due to adding more alloying elements which they are carbide forming element in the Cr5 steel, so there are a lot of carbides in Cr5 steel. Carbides can significantly increase Cr5 steel wear resistance when its diffusely distribute in the matrix. However, once carbides have unusually segregated in the local, microstructure of Cr5 steel will be worsen and form microstructure segregation. Cr5 style heavy backup roll, owing to its larger size, the process of steel ingot solidification will have a mass of carbides which segregated in local, for example, liquid chromatography carbide, Large network carbide and so on [7]. Heat treatment (heating, heat preservation) is one of the effective ways to eliminate or reduce carbide segregation. Carbides in the $\mathrm{Cr} 5$ steel are more sensitive to temperature, generally, they will dissolve into the matrix about $950 \mathrm{C}[8]$. During the follow-up soaking time, alloying elements willhomogenize in the austenite to increase the stability of austenite and prepare for getting quenching martensite[9, 10]. In this paper, influence of quenching temperature on segregated carbides dissolution and properties of $\mathrm{Cr} 5$ steel was studied, lying a certain theoretical basis for later adjusting microstructure and resolving segregation.

\section{2 test content}

In this paper, the material used is Cr5 steel(heat treatment after being forged state), its chemical composition in table 1 . The specific process of heat treatment after being forged is 900C normalizing 
and 800C spheroidizing annealing and $650 \mathrm{C}$ tempering (diffusion hydrogen processing). Test specimens were cut by molybdenum filament wire cutting machine, their size are $10 \mathrm{~mm} \times 10 \mathrm{~mm} \times 10$ $\mathrm{mm}$. Test specimens were heated in the SX-4-10 style chamber electric furnace, heating temperatures are $940 \mathrm{C}, 955 \mathrm{C}, 970 \mathrm{C}, 985 \mathrm{C}$ and $1000 \mathrm{C}$ respectively, soaking time is 60min, and then oil quenching. The samples before and after heat treatment were grinded, polished and corroded(corrodent is $4 \%$ nital) to prepare metallographic specimens. Finally, the microstructure (before and after quenching), phase (before and after quenching), carbide content and hardness were observed, analyzed, calculated and tested by means of scanning electron microscopy, X-ray diffraction, optical software and Rockwell hardness tester.

Table 1 Chemical composition of Cr5 style backup roll(wt,\%)

\begin{tabular}{|c|c|c|c|c|c|c|}
\hline $\mathrm{C}$ & $\mathrm{Mn}$ & $\mathrm{Si}$ & $\mathrm{Mo}$ & $\mathrm{Cr}$ & $\mathrm{Ni}$ & $\mathrm{V}$ \\
\hline $0.45-0.55$ & $0.40-0.50$ & $0.30-0.50$ & $0.50-0.60$ & $4.55-5.50$ & $0.40-0.50$ & $0.10-0.15$ \\
\hline
\end{tabular}

\section{Interpretation of result}

\subsection{Analysis on microstructure and XRD of before quenching}

Fig1 and fig2 are microstructure(carbide segregation) and XRD of Cr5 steel after heat treatment after being forged. It can be seen from Figure 2 the matrix phase of $\mathrm{Cr} 5$ steel after heat treatment after being forged is $\alpha$-Fe, carbides style are $\mathrm{M}_{7} \mathrm{C}_{3}, \mathrm{M}_{23} \mathrm{C}_{6}$ and $\mathrm{M}_{3} \mathrm{C}_{2}$ (M stand for $\mathrm{Cr}, \mathrm{Fe}$ or Mo), and $\mathrm{M}_{7} \mathrm{C}_{3}$ is mainly carbide phase. The carbide of $\mathrm{Cr} 5$ steel has a serious aggregation phenomenon, their morphology features have spherical, ellipsoidal, rod and irregularly distributing in the matrix, as figure 2 show. Carbide is the main reinforcing phase in steel, once carbides have unusually segregated in the local, which will cause the local stress concentration in steel substrate and its microstructure will be worsen. Finally, it will effect $\mathrm{Cr} 5$ steel spalling resistance, hardness uniformity and other special performance.

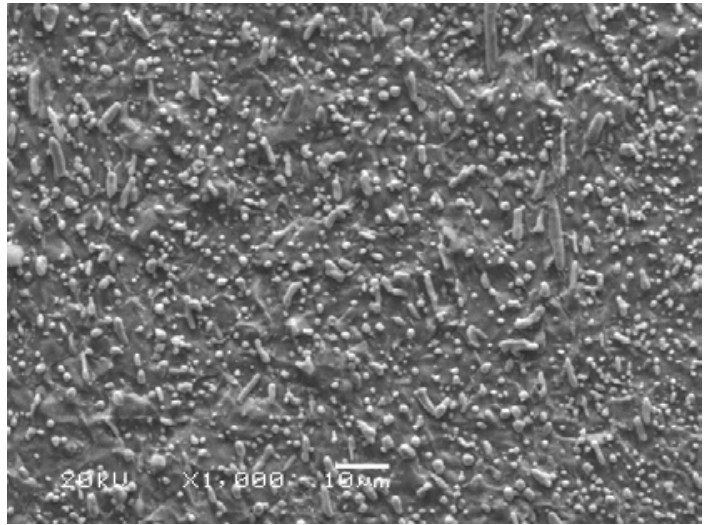

Fig. 1 Microstructure(carbide segregation) of Cr5 steel before quenching before quenching

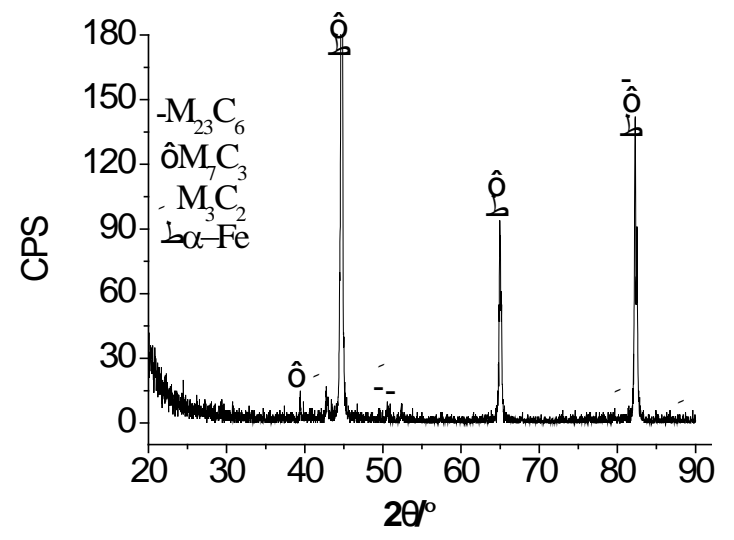

Fig. 2 XRD Cr5 steel

\subsection{Analysis of Cr5 steel microstructure after quenching}

Figure 3 is a set of microstructure pictures under different temperature and the same soaking time quenching, among them a, b, c, d and e corresponding heating temperature are $940 \mathrm{C}, 955 \mathrm{C}, 970 \mathrm{C}$, $985 \mathrm{C}$ and $1000 \mathrm{C}$ respectively, and soaking time are $60 \mathrm{~min}$. Cr5 steel is medium carbon steel, both its mainly alloying element $\mathrm{Cr}$ and matrix element Fe belong to the transitional elements, $\mathrm{Cr}$ atoms are easy to replace $\mathrm{Fe}$ atoms form substitution solid solution or react with carbon generated carbides[11]. The carbides include $\mathrm{Cr}_{3} \mathrm{C}, \mathrm{Cr}_{7} \mathrm{C}_{3}, \mathrm{Cr}_{23} \mathrm{C}_{6}$ and $\mathrm{Cr}_{3} \mathrm{C}_{2}$, and they will change under certain conditions. The temperature of $\mathrm{Cr}_{3} \mathrm{C}$ style carbides dissolving into matrix is above $\mathrm{A}_{\mathrm{c} 1}$ or $\mathrm{A}_{\mathrm{ccm}}$, but $\mathrm{Cr}_{7} \mathrm{C}_{3}$ and $\mathrm{Cr}_{23} \mathrm{C}_{6}$ are over $950 \mathrm{C}[8]$.

It can be seen from Figure 3 the microstructure of test samples after quenching is martensite, residual austenite and not dissolving carbides, the massive spherical, ellipsoidal and rod carbides have disappeared. There are still a lot of granular carbides distributing in martensite in steel when 
quenching temperature(940 C and $955 \mathrm{C}$ ) is lower. The volume fraction of carbides will reduce with the heating temperature continues to rise, it will close to zero when the temperature rise to 1000C.rising temperature not only means to promote the dissolution of carbide, accompanied by the growth of austenite grain. Acicular martensite after quenching is smaller when quenching temperature( $940 \mathrm{C}$ and $955 \mathrm{C}$ ) is lower. austenite grain and acicular martensite began to grow up when quenching temperature rise to the $970 \mathrm{C}$. The austenitic grain size and acicular martensite have fully grown at $1000 \mathrm{C}$.
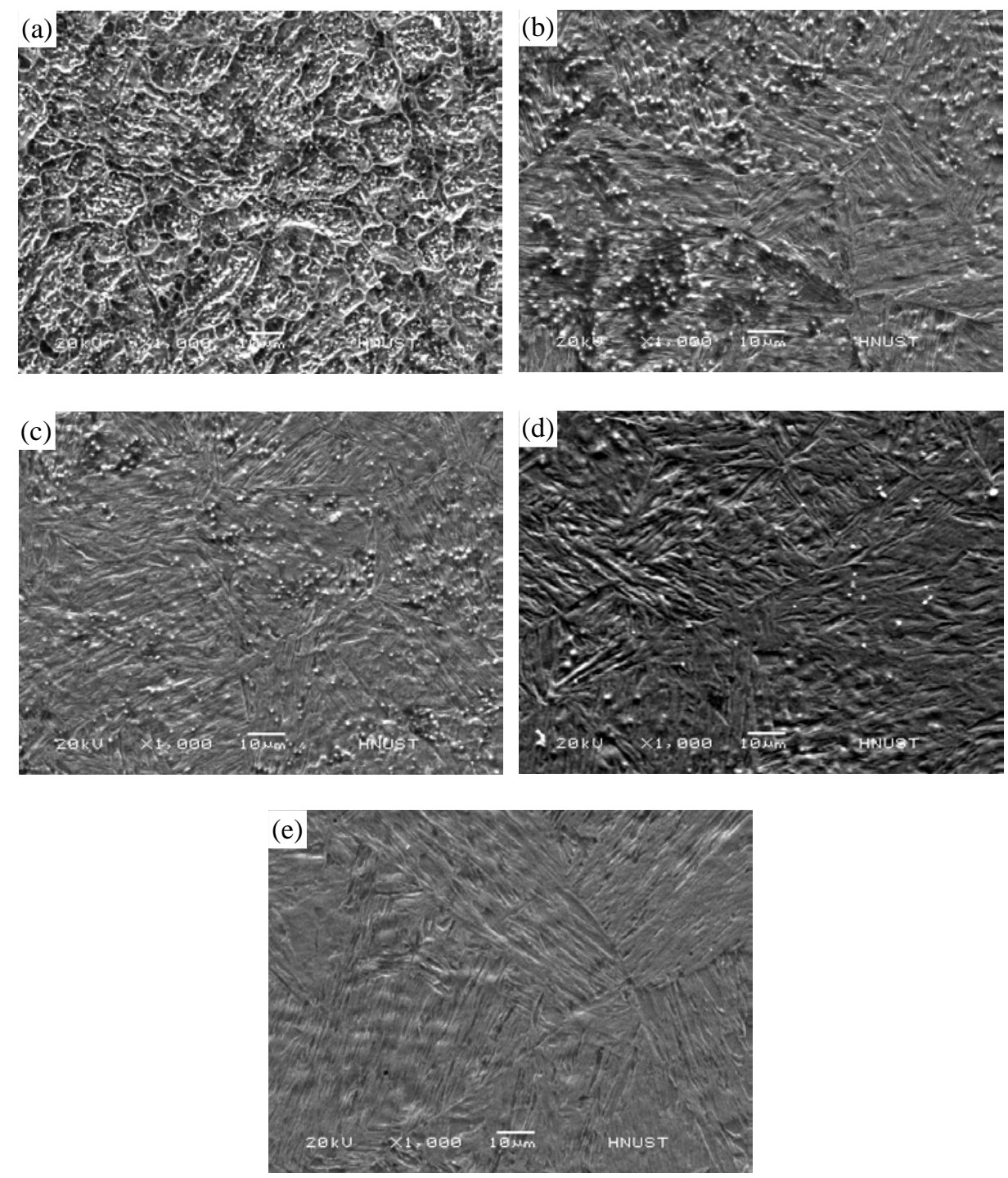

Fig. 3 Microstructure of $\mathrm{Cr} 5$ steel under different temperature quenching (a) 940 C, (b) 955 C, (c) 970 C, (d) 985 C, (e) 1000 C

\subsection{Hardness and volume fraction of Cr5 steel after quenching}

Figure 4 is a variation diagram of hardness and carbide volume fraction of $\mathrm{Cr} 5$ steel under different temperature quenching. It can be seen from the curve of carbide volume fraction in the figure 4 that the temperature of carbide large dissolving into matrix is about $970 \mathrm{C}$, this moment the carbide volume fraction is $7 \%$, the carbide volume fraction continue to reduce with temperature rising, when the temperature reached $1000 \mathrm{C}$, the carbide volume fraction to $1 \%$. Cr5 steel hardness increases and later decreases with the quenching temperature increases, the peak hardness (54 HRC) is achieved in the $970 \mathrm{C}$, as the curve of hardness in the figure 4 show. The hardness of martensite increase rapidly with carbon content aggrandizing when the carbon content of martensite is less than $0.4 \%$, but when carbon content of martensite is more than $0.4 \%$, The hardness of martensite increase slowly with carbon content aggrandizing. Ms point (temperature of martensite transformation) will decrease with carbon content of austenite rising, the hardness of martensite after quenching was increased, but the content of residual austenite also will increase, this cause effect steel hardness decreasing. It can be 
seen from Figure 3 that austenitic grain increase rapidly and microstructure of martensite become bulky when the temperature is more than $970 \mathrm{C}$. The cause of steel hardness decrease rapidly is residual austenite and austenitic grain increasing. When the temperature reached $1000 \mathrm{C}$, the steel hardness to 49 HRC.

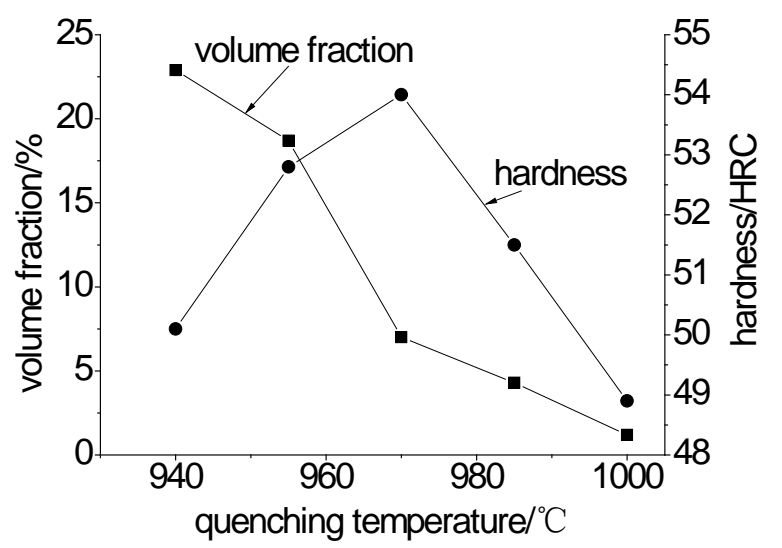

Fig. 4 hardness and carbide volume fraction of Cr5 steel under different temperature quenching

\section{Summary}

1. Carbide style of Cr5 steel after heat treatment after being forged are $M_{7} C_{3}, M_{23} C_{6}$ and $M_{3} C_{2}$, their morphology features have spherical, ellipsoidal, rod and irregularly distributing in the matrix.

2. Carbides in the Cr5 steel are more sensitive to temperature, most carbides will dissolve into matrix and not dissolving into matrix diffusely distribute in the martensite with small granular when the temperature is about $970 \mathrm{C}$. Microstructure of Cr5 steel after quenching will become worse, austenitic grain increase rapidly and martensite become bulky when the temperature is more than 970 C.

3. Cr5 steel hardness increases and later decreases with the quenching temperature increases, the peak hardness (54 HRC) is achieved when the heating temperature is $970 \mathrm{C}$.

\section{References}

[1] Zhang Guo-gang, Wang Ming-jia, Peng Xing-wei, et al. New Multi-element Alloying Cr5 Support Rolls Process Performance Study[J]. Heavy casting and forging, 2011, (4): 16-19

[2] Lu Yin-song, Zhang Zhi-feng, Hu Xue-hui. Manufacturing technology of 5\%Cr strip backup roll [J]. metal working, 2011, (9): 19-23

[3] Zhao Xi-chun. Research on Cr5-Tyle Forged Steel for Backup Roll[J]. Heat Treatment of Metal, 2003, (6): 26-28

[4] Han Rui-min. Production situation and final heat treatment process of forged large-sized backup roll [J]. Heat treatment, 2011, 26(5): 19-23

[5] Zhao Xi-chun. The Manufacturing of 5\% Cr Backup Roll for 2050 Hot Strip Mill of Bao steel[J]. Heavy casting and forging, 2003, (2): 72-75

[6] Qin Cha, Wu Li-zhi, Xu Chang-ling, et al. Study on carbides Piled-up in $\mathrm{M}_{2}$ High-speed Steel[J]. Hot working technology, 2008, 37(14): 31-35

[7] Dai Qi-xun. Metal material science[M]. Chemical industry press, 2005

[8] Zhao Yu, Chen Li, Shi liang. Refining technology of carbide and its effect on properties of GCrl5 steel[J]. Bearing, 2006, (2): 24-27

[9] Li Wen-xing, Liu Zhen-min. Research about carbide high temperature diffusion in GCr15 bearing steel[J]. Hebei metallurgy, 2012, (3): 23-27

[10] Shi De-ke. Fundamentals of materials science[M]. Machinery industry press, 2003 